\title{
Reply to HEP-17-1121
}

Jasmohan S. Bajaj, MD ${ }^{1}$, Zain Kassam MD ${ }^{2,5}$, I. Jane Cox ${ }^{4}, \mathrm{PhD}$, Thomas Gurry, PhD ${ }^{5}$,

Roger Williams, $\mathrm{MD}^{4}$, Eric Alm, $\mathrm{PhD}^{5}$, Binu John, $\mathrm{MD}^{1}$, Mark Smith $\mathrm{PhD}^{2}$, Simon D.

Taylor-Robinson, $\mathrm{MD}^{6}$, Patrick M Gillevet, $\mathrm{PhD}^{3}$

1. Virginia Commonwealth University and McGuire VA Medical Center, Richmond,

Virginia, USA, 2. OpenBiome, Somerville, Massachusetts, USA, 3. George Mason

University, Manassas, Virginia, USA, 4. Institute of Hepatology London, Foundation for

Liver Research, United Kingdom, 5. Massachusetts Institute of Technology, Cambridge,

Massachusetts, USA, 6. Imperial College, London, United Kingdom

\section{Corresponding Author:}

Jasmohan S Bajaj, MD

Division of Gastroenterology, Hepatology and Nutrition,

Virginia Commonwealth University and McGuire VA Medical Center,

1201 Broad Rock Boulevard, Richmond, VA 23221

Email: jasmohan.bajaj@vcuhealth.org

Telephone: (804) 6755802

Fax: (804) 6755816

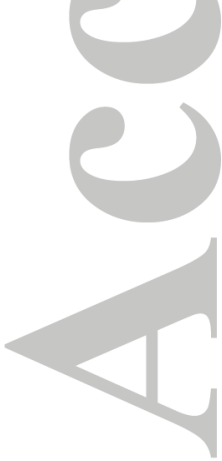

This article has been accepted for publication and undergone full peer review but has not been through the copyediting, typesetting, pagination and proofreading process which may lead to differences between this version and the Version of Record. Please cite this article as doi: 10.1002/hep.29368 
To the Editor

The letter by Mullish et al sets out a few key points about our paper(1). Medical therapy for recurrent hepatic encephalopathy $(\mathrm{HE})$ in the United States consists of first-line lactulose followed by rifaximin in lactulose failure/intolerance(2). Since our inclusion criteria required recurrent $\mathrm{HE}$ with the last episode being $>1$ month ago, patients were on the maximal therapy for at least one month. Rifaximin has been associated with changes in gut microbial functionality and not composition in cirrhosis(3). Our participants were already on rifaximin before being randomized. Therefore all changes that occurred after FMT were likely related to the intervention. We included this population since these patients do not place high on the liver transplant list, yet suffer multiple HE readmissions with significant healthcare burden.

The machine learning to define a rational donor was based on sequences derived from prior HE patients and healthy controls with the assumption that a higher relative abundance of Lachnospiraceae and Ruminococcaccae indicated a healthier microbiota, including their functionality. Current mechanistic understanding of the functional role played by the microbiota in HE is insufficient to select a donor based purely on their presumed functional phenotype, which is why this data-driven approach was adopted. While the exact microbial structure may not have changed radically, we did find an increase in beneficial taxa such as Lactobacillaceae and Bifidobacteriaceae after FMT. The improvement in HE events was over 150 days and not 15 days as suggested in the letter. However, the mechanism of PHES/EncephalApp-Stroop improvement remains under investigation since it may not be related entirely to microbiota dysbiosis. This follows other studies that report only partial change in microbiota after successful FMT(4, 5). We agree that utilizing microbial functionality, rather than composition, could be a better methodology to define future donors and look forward to a greater understanding of the relative importance of microbes and their metabolites in driving clinical outcomes. 


\begin{abstract}
(1)
References:

1. Bajaj JS, Kassam Z, Fagan A, Gavis EA, Liu E, Cox IJ, Kheradman R, et al. Fecal Microbiota Transplant from a Rational Stool Donor Improves Hepatic Encephalopathy: A Randomized Clinical Trial. Hepatology 2017.

2. Vilstrup H, Amodio P, Bajaj J, Cordoba J, Ferenci P, Mullen KD, Weissenborn K, et al. Hepatic encephalopathy in chronic liver disease: 2014 Practice Guideline by the American Association for the Study of Liver Diseases and the European Association for the Study of the Liver. Hepatology 2014;60:715-735.

3. Bajaj JS, Heuman DM, Sanyal AJ, Hylemon PB, Sterling RK, Stravitz RT, Fuchs $\mathrm{M}$, et al. Modulation of the metabiome by rifaximin in patients with cirrhosis and minimal hepatic encephalopathy. PLoS One 2013;8:e60042.

4. Kang DW, Adams JB, Gregory AC, Borody T, Chittick L, Fasano A, Khoruts A, et al. Microbiota Transfer Therapy alters gut ecosystem and improves gastrointestinal and autism symptoms: an open-label study. Microbiome 2017;5:10.

5. Kao D, Roach B, Park H, Hotte N, Madsen K, Bain V, Tandon P. Fecal microbiota transplantation in the management of hepatic encephalopathy. Hepatology 2016;63:339-340.
\end{abstract}

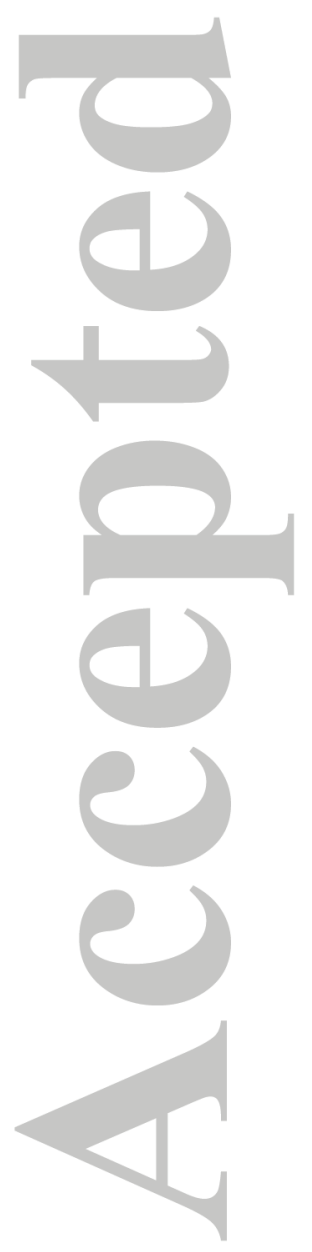

